\title{
Proposing an Index for Cross-District Comparison for Citizen e-Services Provision
}

\author{
Kollapalli Ramesh Babu, A B Sagar, D Venkateswarlu,Y Prabhu Kumar
}

\begin{abstract}
E-Government, the short form of Electronic Government, essentially points to the use of information technologies (typically the Internet) to facilitate the delivery of government information and services, restructure administrative procedures, and enhance citizen participation. E-participation implies "ICT-supported participation in processes involved in government and governance". E-participation is firmly identified with E-government and E-administration interest. Egovernment estimation techniques are not another subject in logical writing. Various international organizations create indices for cross-district comparisons. the new approach introduced to propose a new index called Citizen e-Services Provision Index (CePI). CePI is nothing but composite measure of the quality and capacity of the government in providing ICT related services to its citizens and the level of participation of the citizens in these facilities. This index is a count of how much effort government is keeping in implementing e-governance services, in what areas it is implementing and how well the citizens are participating in these services. We consider four parts of a native for which administrations must be given by the legislature - social, economic, physical and personal. Great administrations by the legislature for these four angles and the e-Participation of the residents in every one of those administrations will plainly infer a decent personal satisfaction of natives and subsequently a high CePI esteem. This paper studies various service areas of implementation of each of these aspects, e-Participation in the services, and a method to calculate the CePI.
\end{abstract}

Keywords: E-governance, Citizen e-Services Provision Index, CePI

\section{INTRODUCTION}

The UN's five guiding principles on e-government objectives are: 1.Building services around citizens choices. 2. Making government and its services more accessible. 3. Social inclusion. 4.Providing information responsibly.5. Using IT and human resources effectively and efficiently [8]. E-Governance has progressively evolved from computerization of government departments to initiatives that capture the finer points of governance, such as citizen centricity, service orientation and transparency.

Revised Version Manuscript Received on 16 September, 2019.

* Correspondence Author

*Kollapalli Ramesh Babu Department of CSE, VJIT, Hyderabad ,Telangana, India .krameshbabucse@vjit.ac.in

A B Sagar, sagar.phdcs@gmail.com

D Venkateswarlu, Department of CSE, VJIT, Hyderabad ,Telangana, India . venkateshwarlud@vjit.ac.in

Y Prabhu Kumar Department of CSE, VJIT, Hyderabad ,Telangana, India.prabhukumar@vjit.ac.in
Governments have long identified the need and potential of ICTs to make legislature facilities available to all the citizens. as a result, it has emerged as a popular phenomenon to provide government services around the Nevertheless, e-governance in an implementation sense is restricted primarily to the extent of computer based Internet right to use to provide services.

Over the decades, many initiatives have been taken by several authorities to bring in an era of e-government. Governments continue trying endeavors to see that all taxpayer driven organizations are accessible to the basic man in his region, through regular help conveyance outlets, and determine viability, straightforwardness, and unwavering quality of such administrations offered reasonably to understand the essential needs of the general people.

In districts where the availability of computers and Internet is fairly low, there is a possibility that the reach of e-governance may be limited. The limited reach of egovernance has made governments look for new technologies, such as mobile phones, to reach the residents and provide public services. This phenomenon has been driven predominantly by the quick growth of mobile phone subscribers in developing districts. Mobile-governance (Mgovernance) is a sub-domain of e-governance. It sees that electronic services are accessible to people via mobile technologies using devices such as mobile phones. These services circumvent the need for conventional physical networks for communications and collaboration. Mobile services are also inexpensive as well as available in most of the rural areas. Increasing the mobile phone accessibility, adaptability and with the millions of subscription base, governments are promoting and using the mobile phone in providing the e-governance services [4]. In the last few years, governments have found that mobile phones can effectively enable citizens and affect the way citizens can avail government's services As opportunities for providing e-governance has increased, several governments have started providing e-services at a far greater rate than before. And with e-government development, many groups with different indices, methodologies and indicators have started to assess the e-governance in






\section{Proposing an Index for Cross-District Comparison for Citizen e-Services Provision}

the developed and developing districts to make crossdistrict comparisons [1]. For example, the E-government Development Index (EGDI) is used to measure the willingness and capacity of national administrations to use information and communication technologies to deliver public services. The E-Government Readiness Index is an index for comparing e-government initiatives around the globe. It is a synthetic index constructed by United Nations agencies to evaluate district's overall readiness. The base for Media Alternatives is using its funding from Making All Voices Count to build on and popularize an Open eGovernance Index [9]. the Quality of the E-Service can be assessed with the help of websites [2]. this paper introduces new idea called Citizen e-Services Provision Index (CePI) which goes beyond the scope of other indices. The idea of this paper is not limited to providing information concerning a government's service, but also about providing necessary services in a qualitative manner so that citizens would prefer to make use of the services provided and fully participate. It considers the provision of eservices by the governments on one hand and also the consumption of those services on the other hand.

\section{CITIZEN E-SERVICES PROVISION INDEX FRAMEWORK}

There are numerous viewpoints throughout individuals' life which they believe are significant. Some of them are relationships, health, spiritual, recreation, financial, work, education, home, etc. We can minimize these aspects and make them into four aspects to make it easier for study. So the four aspects would be - social, economic, physical and personal. Social aspects are related to grievances, security, certificates, transportation facilities, etc. Physical aspects are related to food, shelter, medical, etc. Economic aspects are related to agricultural, business, commercial, etc. Personal aspects are related to utilities services online, spiritual, and academic, entertainment, travel, sport, etc. In this way, an administration needs to give all administrations identified with these viewpoints to make itself subjective in e-governance. Let us briefly study some of the main service implementation areas in these aspects and discuss mechanisms for evaluating the e-Participation value of citizens for that service. These values will help in the effective computation of Citizen e-services Provision Index (CePI).

\section{Social aspects}

Grievances: Grievance Redress Mechanism is an integral part of the hardware of any organization. No organization can profess to be responsible, responsive and easy to understand except if it has built up a productive and compelling complaint review instrument. The
eParticipation of the citizens is measured using unique identification numbers of the citizens.

E-Participation can be estimated dependent on the quantity of uses got online contrasted with the quantity of utilizations got disconnected. If it is purchasing tickets, registering, transactions, etc., we can compare the offline processed count against online processed count. So, for the below areas of implementation, we are not describing how e-participation in each area can be evaluated.

Security: Practically all legislatures have a few destinations for security of its natives. They need to control all types of wrong doing and criminal activities by taking suitable and appropriate preventive measures accompanied by effective detection.

Certificates: Ownership of land, dissolvability, desperate ship, relationship, habitation, religion, and so forth needs accreditation for different motivations behind the resident [3]. Digitizing of every close to home record and keeping up refreshed data on a database as and when it happens may empower natives to get these testaments conveyed to them continuously as the way toward arranging, looking and getting to data will be disentangled. Resident will get their records refreshed by checking the site.

Transportation: Transportation related taxpayer supported organizations to the residents in an advantageous, proficient and straightforward way are a need for natives. To improve e-administration, a portion of the significant e-benefits that legislature could give to its residents are issuance of Smart Card based Driving License \& Registration Certificates, registration of vehicles at Dealer's end, tax payment system, issue of permits, reappearance, etc. it will be evaluated with the help of online processing of tasks compared to offline processing of licenses, certificates, etc. Reservation of tickets for public buses, trains, etc. would also provide a great convenience for the citizens.

\section{Physical aspects}

Food and Civil Supplies: Each legislature has destinations to guarantee supply of nourishment grains at sensible costs to the buyers through the open circulation framework. To deal with the open appropriation framework and make it simpler for residents, governments need to give online administrations to enlistments, supplies conveyance, and so forth. E-Participation can be assessed dependent on the quantity of natives benefiting the online administrations for enrolments, supplies conveyance, and so on when contrasted with the quantity of residents utilizing disconnected techniques.

Housing: Housing assistance can make a significant difference in the economic well-being of low-income families. Governments frequently create policy frameworks that will serve as the foundation for providing housing for everyone [6]. The poor face several constraints in applying for housing allowance from the legislatures. despite of the regular delays in receiving disbursements, 
complicated procedures combined with no option to track applications makes the process cumbersome. So, governments provide e-services for these tasks such as applying for house scheme, house loan, etc.

Health: Government has a responsibility to implement effective public health measures that increase the information available to the public and decision makers, protect people from harm, promote health, and create environments that support healthy behaviours [7]. In addition to information, participation also should be made possible. Through e-Participation, all the citizens able to retrive the schemes and programmes.

\section{Economic Aspects}

Agriculture services: Farmers face problems such as finding buyers at right prices; find aggregators who can buy small lots and sell to big buyers, warehousing, knowing soil's capability and suitability, fake seeds, fertilizers, corruption in utilizing government schemes, difficulty in purchasing required tools and equipment, etc. Governments provide several schemes for the benefit of the farmers. Governments provide e-services for the respective schemes to for efficient and easier utilization.

Business: Citizens look for marketplaces that other transparency and fairness and are also bound by government's rules.

Accountability and transparency are concerns during business dealings. several governments are providing purchasing portals facilitating online procurement of common use goods to address these issues.

Commercial: Commercial services such as tax filing, incorporation of company and other related facilities are very important. They are very complicated tasks for some citizens and offline methods are often time consuming and involve a lot of paper work. In G2C (Government to Citizen), the electronic commerce activities performed between the government and its citizens or consumers, including paying taxes, registering vehicles, and providing information and services are being provided online by several governments.

\section{Personal aspects}

Utilities services online: Some of the utilities services consumed by the public such as electricity, natural gas, water, sewage, telephone, broadband internet services and transportation are very useful to the general people. all the utilities are charged and by and large individuals face various issues while covering the tabs of these utilities. These days in many regions, there are online administrations for the vast majority of the service charge instalments.

Spiritual: Spirituality is a significant perspective for countless natives around the world. There is constantly a Ministry for strict administrations of the residents. For good e-administration, the majority of its administrations ought to be made on the web. Some of the services that a citizen may seek for his/her religious aspect are permission to hold a religious function, travel to religious sites, seek job in religious institutions, etc.

Academic: Residents like to get great and quality training. Access for all to great quality instruction, professional preparing and working environment learning is an essential guideline of social union and financial development. For improving e-administration, governments are giving on the web inductions into the courses. They likewise enable residents to pay the expense on the web. A few governments are in any event, giving courses online by giving the substance of the course online. Various scholarships data is being provided online, and applications are invited, received and processed online.

Jobs: There is no monetary arrangement more significant than occupation creation. Aptitudes advancement is an essential methods for empowering youngsters to make a smooth change to work. Governments are giving on the web entries where the jobless can go after positions. To empower the jobless to end up independently employed, a few advances are additionally being made accessible through online applications and a few aptitude improvement plans are being started [10].

The above discussed aspects and implementation areas are theoretical. They are not inflexible and subsequently are not kept to the predetermined ones. There could be more aspects for consideration and more implementation areas where the e-services may be implemented.

\section{CITIZEN E-SERVICES PROVISION INDEX (CePI) COMPUTATION}

Good e-governance increases inclusiveness of the citizens. In e-governance, inclusiveness happens more through eParticipation. For laymen, complex and exceptionally specialized advances must be maintained a strategic distance from, and a basic interface must be given

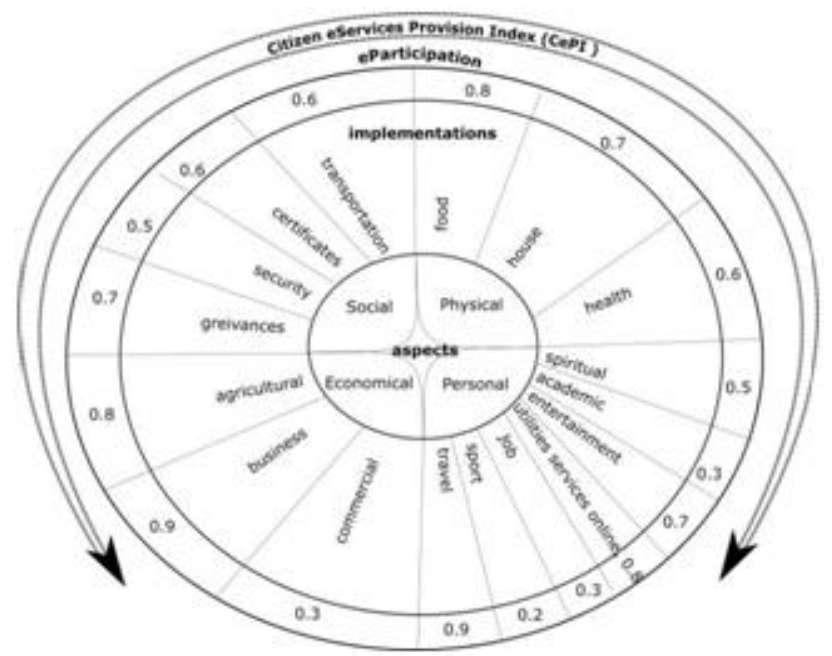

Fig1: Citizen e-Services Provision Index framework 


\section{Proposing an Index for Cross-District Comparison for Citizen e-Services Provision}

Let 'eServiceAreai' represent an implementation area like food, house, health, etc. and 'eParticipationi' represent the online participation level of citizens in that service. If eServiceAreai $=0$, it implies that the government is not off ering the online service for that area, and eServiceAreai $=1$ implies that it is off ering the online service. If eParticipationi $=0$, it implies that citizens participation for that service is zero and eParticipationi $=1$ implies that citizen participation for that service is hundred per cent.

The variable oversaw characterizes whether any of the emerging issues are being settled or not. For any plan, if every one of the issues that emerge and every one of the administrations required are being given by the administration, at that point the estimation of oversaw will be 1 , yet on the off chance that in the event that none of the issues are settled or benefits not accessible, at that point oversaw will be zero. Self-assertive qualities could be appointed if a specific percent of issues were settled and a specific percent of them have not been settled. To keep the estimation of oversaw as 1 or more like 1 , governments should attempt to improve nearby overseeing bodies. Administrations required for the residents might be given at the nearby level through neighbourhood administering bodies.

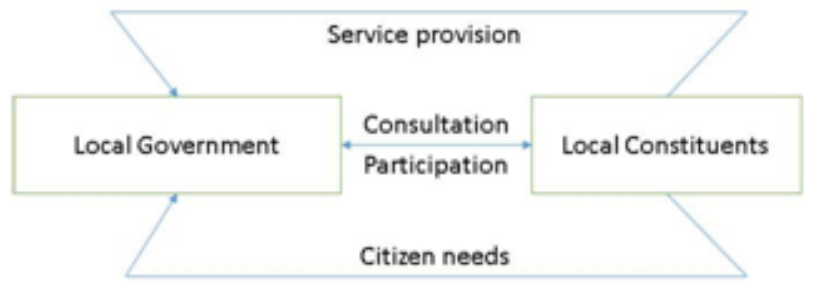

Fig 2: Managing e-services through local governing bodies

The variable oversaw characterizes whether any of the emerging issues are being settled or not. For any eadministration, on the off chance that every one of the issues that emerge are being given by the administration, at that point the estimation of oversaw will be 1 , however on the off chance that in the event that none of the issues are settled, at that point oversaw will be zero. Self-assertive qualities could be doled out if a specific percent of issues were settled and a specific percent of them were not settled.

The Citizen e-Services Provision Index, CePI is computed using the following formula:

$$
\text { CePI }=\sum_{i=1}^{N}\left(\begin{array}{c}
\text { eServiceArea }_{i} * \text { eParticipation }_{i} \\
\left.* \text { managed }_{i}\right)
\end{array}\right.
$$

Where $N$ is the count of eService implementation areas. This is not a constant as the number of areas for implementing e-governance could be increasing or decreasing depending on various conditions such as ICT development, new methods for solving issues, new laws or orders by government, etc. Whatever may be the number that can be finally agreed upon, can be assigned to the variable $N$. However, after deciding upon the value for $N$, the CePI of all governments has to be calculated using the same value for $N$. The maximum value for GeGI is $\mathrm{N}$, and the minimum value is 0 . If CePI is equal to $N$, it implies that the government has implemented e-governance fully in each and every proposed implementation area and is addressing all the aspects of life of a citizen, and the citizens are also fully utilizing all the services through hundred percent eParticipation. If CePI is zero, it implies that the government is not implementing any egovernance in any aspect of life of a citizen or that even if they are implemented; none of the citizens are using those services.

\section{CHARACTERISTICS OF CePI}

Coming up next are a portion of the attributes of the CePI. Expandable: CePI is designed to accommodate more attributes. The aspects can be increased and the implementation areas also can be increased as well without affecting the logic or structure of the formulation.

Measurability: All the attributes in the GeGI computation are quantifiable. Hence CePI is fully measurable without any attributes left out of computation.

Validity: CePI is substantial in light of the fact that it is planned according to the idea it is characterized. It envelopes all the proposed aspects and the implementation areas within those aspects, and considers the eParticipation of the citizens into the implemented services.

Simplicity: CePI is simple and uncomplicated.

Comparability: CePI allows for cross-district comparisons. Consistency: CePI computation does not involve attributes that could become complex, uncomputable or difficult. So, CePI computation is always consistent

Accuracy: CePI computation is accurate and yields consistent results every time.

Scalability - CePI is scalable, meaning that when new aspects or values are to be considered for computation, they can easily be added to the CePI computation without much hassle.

\section{CONCLUSION}

This work introduces another record for making crossregion correlations on account of giving e-administrations to natives. The proposed new list to be specific, Citizen eServices Provision Index (CePI), thinks about four parts of a resident - social, monetary, physical and individual. In every one of these angles, a portion of the model usage territories were considered for the legislature to execute its e-administrations. In social aspect - grievances, security, certificates, and transportation, were considered. In physical aspect- food and civil supplies, housing, and health, were considered. In economic aspect - agricultural, commercial, and business, were considered. In personal utilities services, spiritual, academic, and jobs, were considered. However, it may be noted that this is not rigid. The aspects could be more and the categorization of the




implementation areas into the aspects is also not to be fixed and not to be taken on a strict note. . There could be more aspects and more implementation areas. However, any alteration would not affect the computation of CePI. The computation method was described and the characteristics of the CePI are also described.

\section{REFERENCES}

[1].Olsen et al., M.G. "Benchmarking e-government: A Comparative Review of three International benchmarking Studies". In the Proceedings of the 3rd International Conference on Digital Society (2009), pp. 77-82.

[2].E-Service Quality Evaluation on E-Government Website: Case Study BPJS Kesehatan Indonesia , http:// iopscience.iop.org /article/ 10.1088/ 17426596/801/1/012036/pdf, International Conference on Computing and Applied Informatics 2016 IOP Publishing IOP Conf. Series: Journal of Physics: Conf.Series 801 (2017) 012036 doi:10.1088/1742-6596/801/1/012036

[3].Prasannakumar, B.R. (2001), e-Governance and Service DeliveryScope and Implementation Issues. Institute of Management in Government Thiruvananthapuram, Kerala, India

[4].E-Governance - A challenge for India, International Journal of Advanced Research in Computer Engineering \& Technology (IJARCET) Volume 2, Issue 3, March 2013, ISSN: 22781323

[5].Draft Consultation Paper on Mobile Governance Policy Framework, National e-Governance Division, March 2011, http://www. mit.gov.in/ whatsnew/

[6].https://www.devex.com/news/why-proper-housing-for-thepoor-makes-economic-sense-86785 Accessed on 12-08-2017.

[7].Government's Role in Protecting Health and Safety Thomas R. Frieden, M.D., M.P.H. N Engl J Med 2013; 368:1857-1859May 16, 2013DOI: 10.1056/NE-JMp1303819

[8].United Nations, A Global Survey of E-government, 2002. URL: https://publicadministration.un.org/egovkb/portals/egovkb/document s/un/e nglish.pdf Accessed on 5 Sept 2017

[9].The Changing Role of the Citizen in the E-governance and Edemocracy Equation by Cathia Gilbert Riley, Sept 2003 http://www.rileyis.com/publications...

[10].URL:http://neweconomicperspectives.blogspot.com/2009/08/jobguarantee.html. Accessed on 15 Sept 2017

\section{AUTHORS PROFILE}

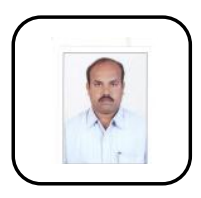

Dr.K.Ramesh babu , Associate Professor from CSE , Vidya Jyothi Institute of Technology. He has received $\mathrm{Ph} . \mathrm{D}$ from Central University, Hyderabad. He is a Life Member of CSI. His research interest areas are Computer Networks, Network Security, and Machine Learning.

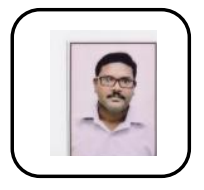

A B Sagar is an Informatics Officer in National Informatics Center. His research interests include micropayment schemes, ethics in information technology, web development, software engineering, etc. He has published several national and international journals and conferences.

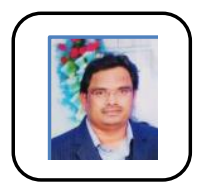

D.Venkateshwarlu Associate Professor in Dep of Computer Science and Engineering VidyaJyothi Institute of Technology,Hyderabad. His research interest areas Data Mining, Big Data, and IoT

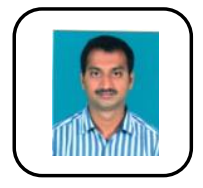

Y Prabhu Kumar Department of CSE,VJIT,Hyderabad. He is currently pursuing Ph.D. from KL university, His research interest areas Data Mining, and Big Data 